\title{
A Fluorous Biphasic Solvent Extraction System for Lanthanides with a Fluorophilic $\beta$-Diketone Type Extractant
}

\author{
Etsuko Nakamura, Yuki Hiruta, Takafumi Watanabe, Naoko Iwasawa, Daniel CitTerio, ${ }^{\dagger}$ and \\ Koji SUZUKI ${ }^{\dagger}$
}

Department of Applied Chemistry, Faculty of Science and Technology, Keio University, 3-14-1 Hiyoshi, Kohoku, Yokohama, Kanagawa 223-8522, Japan

\begin{abstract}
The properties of a fluorous solvent extraction system for trivalent lanthanide metal ions are reported. A fluorinated extractant, 4,4,5,5,6,6,7,7,8,8,9,9,9-tridecafluoro-1-(2-thienyl)-1,3-nonanedione, and HFE-7200 $\left(\mathrm{C}_{4} \mathrm{~F}_{9} \mathrm{OC}_{2} \mathrm{H}_{5}\right)$ as the extraction solvent were chosen. With this fluorous extractant/solvent combination, higher extraction ratios and separation factors compared to a conventional organic solvent system (thenoyltrifluoroacetone in $\mathrm{CHCl}_{3}$ ) were achieved for 5 heavy lanthanide ions ( $\mathrm{Lu}, \mathrm{Yb}, \mathrm{Tm}, \mathrm{Er}$ and $\mathrm{Ho}$ ). On the other hand, light lanthanide ions (Nd, $\mathrm{Pr}, \mathrm{Ce}$ and $\mathrm{La}$ ) are hardly extracted, therefore enabling the mutual separation of light lanthanides from middle or heavy lanthanide ions.
\end{abstract}

Keywords Solvent extraction, fluorous solvent, lanthanide, mutual separation

(Received April 13, 2015; Accepted July 16, 2015; Published September 10, 2015)

\section{Introduction}

Recently, rare earths are being widely used elements in a variety of functional materials. ${ }^{1-3}$ For example, europium(III) and terbium(III) with their specific fluorescence are applied in fluorescent lamps or as labeling reagents, among others. Neodymium and dysprosium are essential components in permanent magnets. Since the supply and mining of rare earths are geographically limited, there is strong demand for suitable recycling methods, in order to secure a stable and continuous supply of these elements. However, recycling efforts are challenging, because the lanthanide ions have similar chemical properties, such as ionic radii, electric charge in solution and hardness as Lewis acids, which makes their separation very difficult. Therefore, it has been attempted to selectively isolate a particular lanthanide or to improve the mutual separation capacity.

For the recycled use of lanthanides, the most widely applied method for purification is solvent extraction. For decades, the solvent extraction of metal ions with a chelating agent has attracted considerable attention. There are various factors that influence the extraction efficiency, such as the choice of extractants (chelating agents), synergists and solvents. As extractants for rare earth metal ions, organophosphorous compounds, such as 2-(ethylhexyl)phosphonic acid mono-2ethylhexyl ester (PC-88A) ${ }^{4}$ and 2-(ethylhexyl)phosphoric acid (D2EHPA), ${ }^{5,6}$ as well as $\beta$-diketone compounds, such as

† To whom correspondence should be addressed.

E-mail: suzuki@applc.keio.ac.jp (K. S.); citterio@applc.keio. ac.jp (D. C.)

Y. H. Present address: Division of Physical Pharmaceutical Chemistry, Faculty of Pharmacy, Keio University, 1-5-30 Shibakoen, Minato, Tokyo 105-8512, Japan. thenoyltrifluoroacetone (Htta), pivaloyltrifluoroacetone (Hpta) and hexafluoroacetylacetone (Hhfa), are known for their separation efficiency.7,8 Recently, Goto and coworkers synthesized new "green" rare-earth extractants, which are based on a dioctyldiglycol amic acid (DODGAA) structure, ${ }^{9,10}$ solely composed of carbon, hydrogen, oxygen and nitrogen atoms. They achieved an extraction performance superior to that of conventional CHON-type extractants (e.g. carboxylic-acid-type compound 2-ethyl-2-methylheptanoic acid Versatic 10) and comparable to common organophosphorous-based extractants (e.g. PC-88A and D2EHPA). ${ }^{11}$

Furthermore, synergistic extraction has been studied extensively over the past decades. The addition of an electrically neutral ligand or a Lewis base enhances not only the extractability, but also the efficiency of mutual separation, because these synergistic ligands enhance the lipophilicity of the metal complex. Examples of compounds used as synergists for synergistic extraction are bipyridine, pyridine, ${ }^{12}$ and crown ethers, ${ }^{13,14}$ which all show an enhancement of specific extraction.

Finally, also the extraction solvent significantly affects the extraction efficiency. ${ }^{15}$ For example, in the extraction of lanthanides with Htta, the dependence of the extraction constant values on the extraction solvents has been confirmed. . $^{7,16-19}$ Since the toxic and flammable characteristics of many organic solvents are detrimental to the environment, substitutes have been investigated. As an example, ionic liquids (ILs) have gained attention as candidates for the substitution of organic solvents. Nakashima et al. first reported on lanthanide extraction using 1-butyl-3-methylimidazolium hexafluorophosphate as the extraction solvent in combination with octyl(phenyl)- $N, N$ diisobutylcarbamoylmethyl phosphine oxide, CMPO, which is a promising extractant for the separation of actinides. ${ }^{20}$ Later on, several other reports concerning the use of ILs with various extractants have been presented..$^{21,22}$

Due to their unique properties, fluorous solvents (fluorocarbons, 


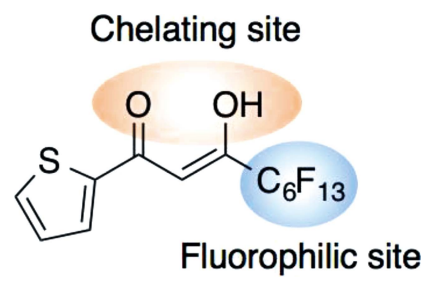

Fig. 1 Chemical structure of the fluorophilic extractant compound 3.

mostly perfluorinated alkanes, ethers and tertiary amines) have attracted much interest in a wide range of fields in organic chemistry, biochemistry, and material science. ${ }^{23-26}$ The water solubility in fluorous solvents is remarkably low. Fluorous solvents are nontoxic, non-flammable, chemically stable, and immiscible with water. Horvath and Rabai investigated a fluorous biphasic system, which offers great integration of a homogeneous reaction and subsequent separation using a fluorous tag. ${ }^{27,28}$ Perfluorocarbons can dissolve only fluoroustagged (highly fluorinated) compounds, and are immiscible with non-fluorinated organic solvents at ambient temperature. Thus, the application of fluorous compounds for extraction is widely spread. Weber and coworkers studied the extraction of pyridines and porphyrin from an organic solvent to fluorous solvents using a carboxylic acid receptor. ${ }^{29}$ Kondo and coworkers examined the extraction of organic acids into a hydrofluoroether using tri- $n$-butylphosphate (TBP) and a mixture of TBP and tri- $n$-octylamine (TOA). ${ }^{30}$ The Buhlmann group's research on fluorous chemistry applied to ion-selective electrodes (ISEs) revealed that ionophore-doped fluorous membranes showed drastically enhanced selectivity, because of their extremely low polarity. ${ }^{31}$ The selectivities achieved for cations were found to be significantly larger than in the case of non-fluorous membrane materials, and spanned a range of sixteen orders of magnitude, which is 8 orders of magnitude larger than that for conventional ISEs. These results were attributed to the absence of solvation of the cations in the fluorous membrane phase.

Despite increasing interest in fluorous solvents, there are few reports concerning metal extraction using fluorous solvents as an extracting solvent. ${ }^{32-34}$ Therefore, we were interested in the possibility of achieving higher extraction selectivity and mutual separation of rare-earth metal ions by using a fluorous solvent instead of organic solvents.

This work reports on a basic study involving the solvent extraction of lanthanide ions from an aqueous phase to a hydrofluoroether (HFE-7200 $\left[\mathrm{C}_{4} \mathrm{~F}_{9} \mathrm{OC}_{2} \mathrm{H}_{5}\right]$ ) using the highly fluorinated $\beta$-diketone extractant compound 3 (Fig. 1), ${ }^{35}$ the structure of which is based on thenoyltrifluoroacetone (Htta), a widely used extractant of rare earths. Compound $\mathbf{3}$ has been shown to form complexes with trivalent lanthanide ions, and their luminescence properties have been reported..$^{35,36}$ The $\beta$-diketone moiety of compound $\mathbf{3}$ acts as a metal chelating site, and the fluoroalkyl chain renders the extractant soluble in fluorous solvents, which is essential for the application targeted in this work. The extractability of lanthanide ions was evaluated as a function of the extractant concentration; the extraction constants, $K_{\text {ex }}$, of 5 heavier lanthanides were experimentally determined. Next, a comparison of the extractability depending on the extractant (Htta and compound 3) or the solvent was performed over the whole lanthanide series. Finally, the $\mathrm{pH}$ response and the reusability of compound $\mathbf{3}$ were investigated.

\section{Experimental}

\section{Reagents and chemicals}

All reagents for synthesizing the fluorophilic extractant (compound 3) were purchased from the following commercial suppliers, and were used without further purification: Wako Pure Chemical (Osaka, Japan), Tokyo Kasei Industry (Tokyo, Japan) and Aldrich Chemical (St. Louis, MO). Thenoyltrifluoroacetone (Htta) was obtained from Aldrich Chemical. Solvents used as extraction media, chloroform and Novec ${ }^{\mathrm{TM}} 7200$ (hydrofluoroether, HFE-7200), were purchased from Kanto Chemical (Tokyo, Japan) and Sumitomo 3M Ltd. (Tokyo, Japan), respectively.

\section{Apparatus}

${ }^{1} \mathrm{H}-\mathrm{NMR},{ }^{19} \mathrm{~F}-\mathrm{NMR}$ and ${ }^{13} \mathrm{C}-\mathrm{NMR}$ spectra were recorded at room temperature on a JEOL ECA-500 spectrometer at 500 and $125 \mathrm{MHz}$, respectively. Chemical shifts of ${ }^{1} \mathrm{H}-\mathrm{NMR}$ are relative to an internal standard of tetramethylsilane $(\delta=0.0 \mathrm{ppm})$, and coupling constants are given in Hz. High-resolution mass spectra were obtained on a Waters Xevo G2-SQTof MS (Waters LCT Premier XE). An ICPS-8000 inductively coupled argon plasma atomic emission spectrometer (Shimadzu, Kyoto, Japan) was used for determining the concentration of each metal ion in aqueous solution. The $\mathrm{pH}$ values were verified using a $\mathrm{pH}$ meter, HM-30R (Toa DKK, Tokyo, Japan), with a glass $\mathrm{pH}$ electrode. The deionized water used had a resistivity of $18.2 \mathrm{M} \Omega$ at $298 \mathrm{~K}$.

\section{Synthesis of compound 3}

The synthesis route for the fluorophilic extractant $\mathbf{3}$ is shown in Scheme 1. Compound $1(6.94 \mathrm{~g}, 55.1 \mathrm{mmol})$ was dissolved in diethylether $(350 \mathrm{~mL})$. After the addition of $28 \% \mathrm{MeONa}$ in $\mathrm{MeOH}(15 \mathrm{~mL}), 2(22.8 \mathrm{~g}, 34.5 \mathrm{mmol})$ was added and the solution was stirred for $20 \mathrm{~h}$ at room temperature. After the reaction was completed, the $\mathrm{pH}$ of the solution was lowered to acid condition by the addition of $1 \mathrm{M} \mathrm{HCl}(100 \mathrm{~mL})$. The acidic aqueous phase was extracted with diethylether 3 times. Washing of the combined organic layer twice with water and once with brine, followed by drying over $\mathrm{Na}_{2} \mathrm{SO}_{4}$, and solvent evaporation, resulted in the appearance of a crystalline raw product. Purification was achieved by recrystallization. For this purpose, the raw product was dissolved in acetone $(90 \mathrm{~mL})$ and left standing until crystallization. After vacuum filtration and washing with cold acetone, compound $\mathbf{3}$ was obtained as yellowish white crystals $(17.2 \mathrm{~g}, 72.2 \%)$. ${ }^{1} \mathrm{H}-\mathrm{NMR}\left(\mathrm{CDCl}_{3}\right.$, $500 \mathrm{MHz}) \delta(\mathrm{ppm}): 7.86(\mathrm{dd}, 1 \mathrm{H}, J=4.0,1.0 \mathrm{~Hz}), 7.78(\mathrm{dd}$, $1 \mathrm{H}, J=5.0,1.0 \mathrm{~Hz}), 7.22(\mathrm{dd}, 1 \mathrm{H}, J=4.0,5.0 \mathrm{~Hz}), 6.48(\mathrm{~s}$, 1H). ${ }^{13} \mathrm{C}-\mathrm{NMR}\left(\mathrm{CDCl}_{3}, 500 \mathrm{MHz}\right) \delta(\mathrm{ppm}): 182.1,173.4(\mathrm{t}, J=$ $26.8 \mathrm{~Hz}), 139.2,135.4,132.8,128.9,120.7$ (t, $26.9 \mathrm{~Hz}), 118.4$ $(\mathrm{t}, 32.8 \mathrm{~Hz}), 116.1(\mathrm{t}, J=32.8 \mathrm{~Hz}), 114.1-107.8(\mathrm{~m}), 106.4(\mathrm{q}$, $J=38.8 \mathrm{~Hz}) .{ }^{19} \mathrm{~F}-\mathrm{NMR}\left(\mathrm{CDCl}_{3}, 500 \mathrm{MHz}\right) \delta(\mathrm{ppm}):-120.3(\mathrm{t}$, $J=15.6 \mathrm{~Hz}, 3 \mathrm{~F}),-121.6(\mathrm{~s}, 2 \mathrm{~F}),-122.3(\mathrm{~s}, 2 \mathrm{~F}),-122.7(\mathrm{~s}, 2 \mathrm{~F})$, $-126.0(\mathrm{~s}, 2 \mathrm{~F})$. HRMS: calculated for $\mathrm{C}_{13} \mathrm{H}_{5} \mathrm{~F}_{13} \mathrm{O}_{2} \mathrm{~S} 472.9881$ $[\mathrm{M}+\mathrm{H}]^{+}$; found 472.9909 .

\section{Extraction procedure}

Aqueous solutions containing a lanthanide ion $\left(\mathrm{Ln}^{3+}, 3.6 \times\right.$ $10^{-5} \mathrm{M}$ ) were prepared by adding standard metal solutions to acetate buffer solutions $(I=0.1 \mathrm{M})$. The extraction phases were prepared by dissolving the extractant $\mathbf{3}$ or $\mathrm{Htta}$ (various concentrations) in HFE-7200 or chloroform. Equal volumes $(5 \mathrm{~mL})$ of aqueous solutions and extraction solvents were mixed in a $50 \mathrm{~mL}$ centrifugation tube and shaken at $250 \mathrm{rpm}$ for $3 \mathrm{~h}$ at 
<smiles>COC(=O)[CH+]C(C)=O</smiles>

1 2

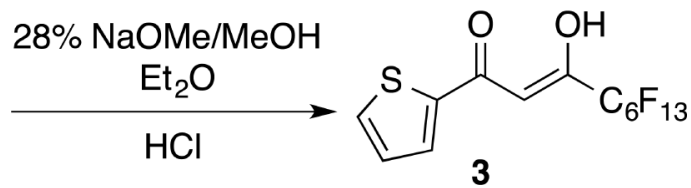

Scheme 1 Synthesis route of the fluorophilic extractant compound $\mathbf{3}$

$25^{\circ} \mathrm{C}$. After phase separation by centrifugation $(5500 \mathrm{rpm}, 3$ $\min$ ), $\mathrm{pH}$ values of aqueous phases were measured with a $\mathrm{pH}$ meter. To reduce the matrix effect, the aqueous phase was ten-times diluted with $0.3 \mathrm{M}$ nitric acid and the concentration of lanthanide ions $\left(\left[\mathrm{Ln}^{3+}\right]\right)$ was determined with ICP-AES. After forward extraction, $5 \mathrm{~mL}$ of $0.3 \mathrm{M}$ nitric acid was added to the organic phase as a stripping solution, followed by shaking for $30 \mathrm{~min}$. After centrifugation, $\left[\mathrm{Ln}^{3+}\right]$ in aqueous solutions were measured to determine the degree of back extraction. The extraction ratio $(E)$, distribution ratio $(D)$ and extraction constant $\left(K_{\mathrm{ex}}\right)$ were determined based on the experimentally measured lanthanide concentrations $\left[\mathrm{Ln}^{3+}\right]$ and $\mathrm{pH}$ values from the following equations:

$$
\begin{aligned}
& E(\%)=\left(\left[\operatorname{Ln}^{3+}\right]_{\mathrm{aq}, 0}-\left[\operatorname{Ln}^{3+}\right]_{\mathrm{aq}}\right) /\left[\operatorname{Ln}^{3+}\right]_{\mathrm{aq}, 0} \times 100, \\
& D=\left[\operatorname{Ln}^{3+}\right]_{\mathrm{ex}} /\left[\mathrm{Ln}^{3+}\right]_{\mathrm{aq}}, \\
& \log D=\log K_{\mathrm{ex}}+n \log [\text { extractant }]+n \mathrm{pH},
\end{aligned}
$$

where the indices "aq" and "ex" represent the aqueous phase and extraction phase, respectively, and "0" denotes the initial metal ion concentration. The separation factor between two elements, A and B, was determined from

$$
\beta_{\mathrm{AB}}=K_{\mathrm{ex}}(\mathrm{A}) / K_{\mathrm{ex}}(\mathrm{B}) .
$$

\section{Results and Discussion}

\section{Molecular structure and synthesis}

The molecular structure of the fluorophilic extractant $\mathbf{3}$ with a $\beta$-diketone metal chelating site chosen for this work is closely related to that of Htta. The extended perfluorinated alkyl chain provides the affinity required for the use in a fluorous solvent. $\beta$-diketone derivatives are well known as promising extractants for lanthanides and transition metal ions. It has been reported that Htta forms stable 3:1 complexes with trivalent metal ions. ${ }^{8}$ Therefore, identical complex stoichiometry can be expected for the fluorophilic derivative. As shown in Scheme 1, compound 3 is readily accessible by synthesis from commercially available starting materials in a single reaction step. The integral value for the proton in the $\alpha$-position to the carbonyl group at $6.48 \mathrm{ppm}$ in the ${ }^{1} \mathrm{H}-\mathrm{NMR}$ spectrum (electronic supplementary information), being close to 1 , indicates that compound $\mathbf{3}$ is predominantly present in its enolic form.

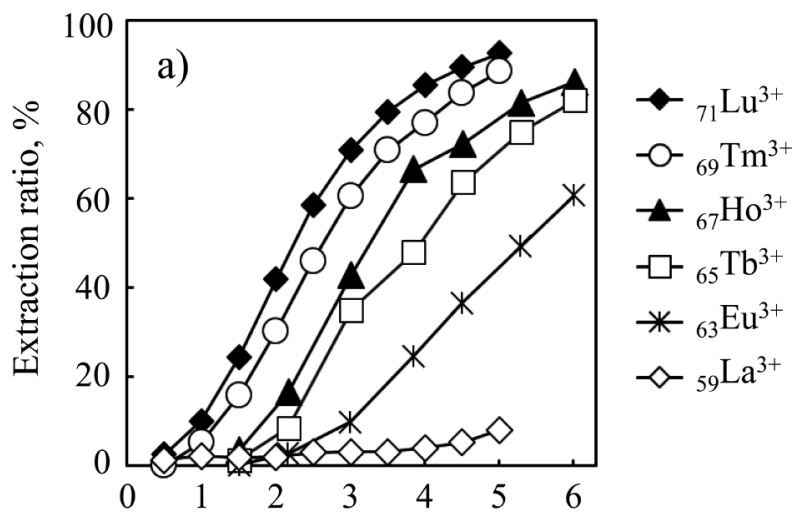

$[3] / \mathrm{mM}$

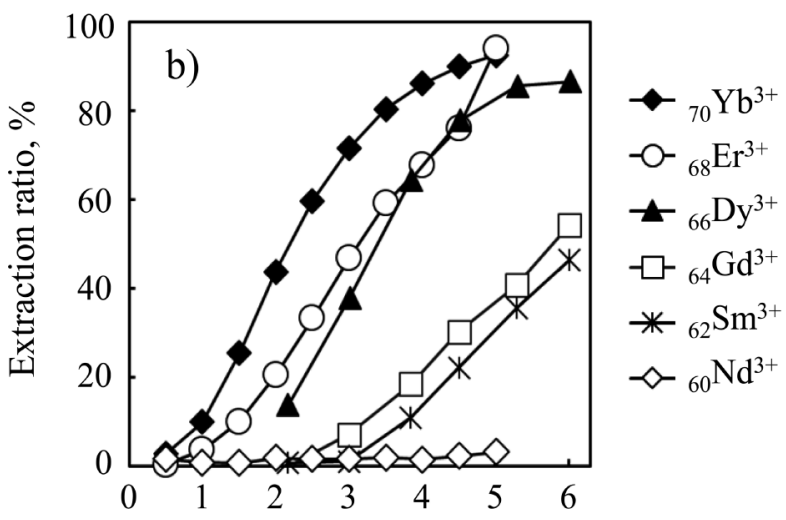

$[3] / \mathrm{mM}$

Fig. 2 Extractant concentration-dependent extraction ratio of lanthanides with 3 in HFE-7200 (acetate buffer pH 5.3): (a) odd atomic number (b) even atomic number.

\section{Determination of the extraction ratio}

Figure 2 shows the extractant concentration-dependent extraction ratios achieved with compound $\mathbf{3}$ in fluorous HFE7200 (pH of the aqueous acetate buffer phase 5.3). Generally, in chelate-based extraction, heavier lanthanides show superior extractability compared to lighter ones owing to their relatively strong electrostatic interaction ability. ${ }^{12,37}$ The same trend was confirmed in this fluorous experimental system. Under the

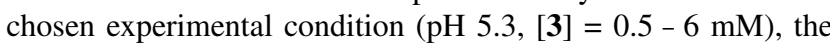
light lanthanides $\left(\mathrm{La}^{3+}\right.$ and $\left.\mathrm{Nd}^{3+}\right)$ were hardly extracted.

Determination of the extraction constant and confirmation of 1:3 complex stoichiometry

To confirm the complex stoichiometry in a fluorous solvent with 5 heavy trivalent lanthanide ions ( $\mathrm{Lu}, \mathrm{Yb}, \mathrm{Tm}, \mathrm{Er}$ and $\mathrm{Ho}$ ), as well as to estimate the extraction constants, $K_{\text {ex }}$, of $\mathbf{3}$ for lanthanide ions, the relationship between the concentration of 3 and the distribution ratio, $D$, was evaluated (Fig. 3). In each case, a linear correlation with a slope of close to three was observed (Fig. 3). The complex stoichiometries and extraction constants of the 5 lanthanide ions were calculated based on the slopes and intercepts of the linear-regression curves (Fig. 3) based on Eq. (3). The experimentally determined extraction constants are listed in Table 1 . The separation factors $\beta$ for each pair of elements, calculated from the data shown in Table 1 using Eq. (4), are shown in Table 2. The results reveal that the fluorous extraction system (3/HFE-7200) shows higher 


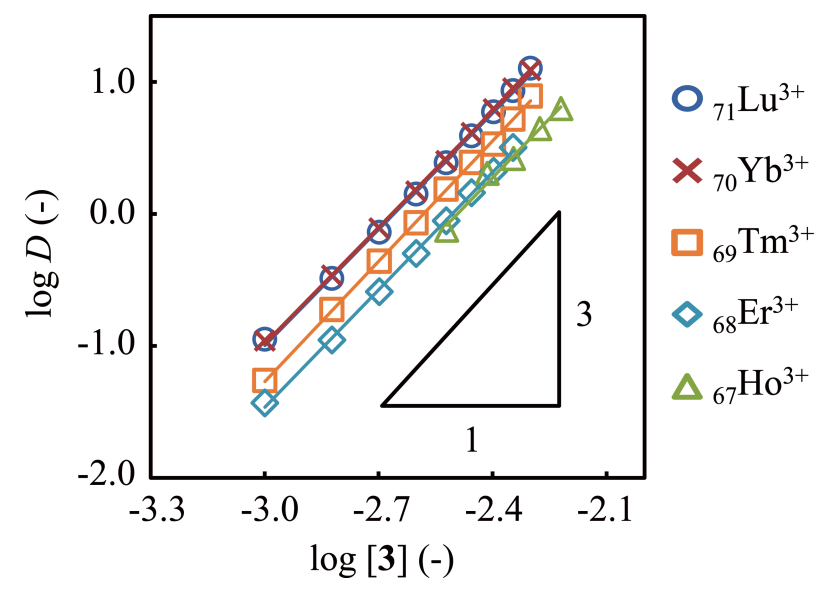

Fig. 3 Relationship between the distribution ratio and the concentration of $\mathbf{3}$ in the extraction phase ( $\mathrm{pH} 5.3$ in aqueous phase, acetate buffer).

Table 1 Extraction constants, $\log K_{\text {ex }}$, for five heavy lanthanides

\begin{tabular}{ccc}
\hline & \multicolumn{2}{c}{ Extraction constant $\log K_{\mathrm{ex}}$} \\
\cline { 2 - 3 } & Fluorous $^{\mathrm{a}}$ & Organic $^{\mathrm{b}}$ \\
\hline${ }_{71} \mathrm{Lu}$ & -7.91 & -8.67 \\
${ }_{70} \mathrm{Yb}$ & -7.83 & -8.31 \\
${ }_{6}{ }_{9} \mathrm{Tm}$ & -8.16 & -8.69 \\
${ }_{68} \mathrm{Er}$ & -8.20 & -8.71 \\
${ }_{67} \mathrm{Ho}$ & -8.58 & -8.70 \\
\hline
\end{tabular}

a. Compound $\mathbf{3}$ in HFE-7200, b. Htta in chloroform.

Table 2 Separation factors, $\beta$

\begin{tabular}{lcc}
\hline & \multicolumn{2}{c}{ Separation factor $\beta$} \\
\cline { 2 - 3 } Element pair & Fluorous & Organic \\
\hline & 1.19 & 2.28 \\
${ }_{71} \mathrm{Lu} /{ }_{70} \mathrm{Yb}$ & 1.78 & 1.05 \\
${ }_{71} \mathrm{Lu} /{ }_{69} \mathrm{Tm}$ & 1.96 & 1.10 \\
${ }_{71} \mathrm{Lu} /{ }_{68} \mathrm{Er}$ & 4.69 & 1.10 \\
${ }_{71} \mathrm{Lu} /{ }_{67} \mathrm{Ho}$ & 2.12 & 2.40 \\
${ }_{70} \mathrm{Yb} /{ }_{69} \mathrm{Tm}$ & 2.33 & 2.51 \\
${ }_{70} \mathrm{Yb} /{ }_{68} \mathrm{Er}$ & 5.59 & 2.50 \\
${ }_{70} \mathrm{Yb} /{ }_{67} \mathrm{Ho}$ & 1.10 & 1.05 \\
${ }_{6} \mathrm{Tm} /{ }_{68} \mathrm{Er}$ & 2.64 & 1.04 \\
${ }_{6} \mathrm{Tm} /{ }_{67} \mathrm{Ho}$ & 2.40 & 1.01 \\
${ }_{68} \mathrm{Er} /{ }_{67} \mathrm{Ho}$ & &
\end{tabular}

extraction ability compared with the conventional organic solvent system (Htta/chloroform). In addition, in terms of the separation factors, $\beta$, there are differences between the fluorous and the organic solvent systems. In particular, the separation factors for Ho and other elements were significantly larger for the fluorous solvent system compared to those for the conventional organic solvent system. To the best of our knowledge, this is the first time to report on extraction constants and separation factors of lanthanides using a fluorous solvent as an extraction medium.

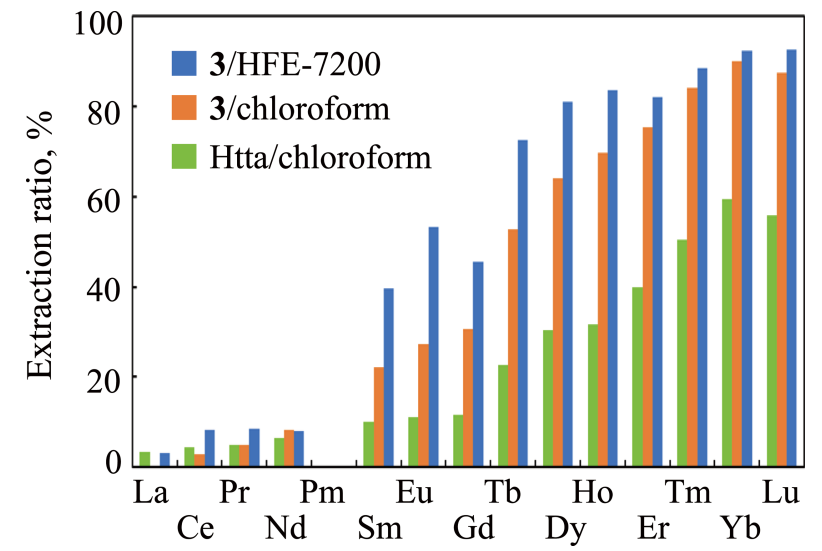

Fig. 4 Variation of the extraction ratio across all 14 lanthanides under identical experimental conditions. Aqueous phase: $\mathrm{pH} 5.3$ in acetate buffer, extracting phase: $5 \mathrm{mM}$ of extractant; blue: $3 / \mathrm{HFE}$ 7200; orange: 3/chloroform; green: Htta/chloroform.

Influence of extraction solvent and extractant on complete lanthanide series

Figure 4 shows the results of extraction experiments performed with all 14 lanthanide ions and various extractant/solvent combinations (5 mM of extractant at $\mathrm{pH} 5.3$ ). It can be concluded that the fluorinated extractant $\mathbf{3}$ paired with the fluorous solvent HFE-7200 enabled the highest extraction ratios for all lanthanides. The different extraction effects observed for the use of $\mathbf{3}$ in chloroform or in the fluorous solvent system might be attributed to the different solubility of the lanthanide complexes of $\mathbf{3}$ in these two solvents. In addition, there is also an apparent difference when using compound $\mathbf{3}$ or $\mathrm{Htta}$ in chloroform as the extraction solvent. It is assumed that the longer fluoroalkyl chain of $\mathbf{3}$ increases the electron withdrawing properties compared to Htta, promoting the formation of the enolic form for extractant 3 , and lowering its $\mathrm{p} K_{\mathrm{a}}$ value.

\section{Extraction efficiency of $\mathbf{3}$ as a function of $\mathrm{pH}$}

Figure 5 indicates the extraction behavior for $\mathrm{Dy}^{3+}$ and $\mathrm{Nd}^{3+}$ ions from water into HFE-7200 or chloroform with $6 \mathrm{mM} 3$ as a function of $\mathrm{pH}$. The experiment revealed that at a $\mathrm{pH}$ value around 5, though $\mathrm{Nd}^{3+}$ was hardly extracted, $\mathrm{Dy}^{3+}$ was efficiently extracted with 3 in both solvent systems, with the efficiency in HFE-7200 being higher than that in chloroform.

\section{Lanthanide separation}

With regard to a potential practical application, an example where the separation of the elements is regarded as being particularly relevant has been investigated. Dy and $\mathrm{Nd}$ were chosen for this purpose, because both elements are important and costly materials in permanent magnets, and their mutual separation is highly desired. As shown in Fig. $6, \mathrm{Nd}^{3+}$ was hardly extracted by any extractant/solvent combination, while the extraction ratio of $\mathrm{Dy}^{3+}$ increased depending on the extractant concentration. In particular, the increasing extraction ratio of the fluorous 3/HFE-7200 system is significant. This result suggests that the fluorous system is suitable for $\mathrm{Dy}^{3+} / \mathrm{Nd}^{3+}$ separation at an extractant concentration of around 5-6 mM.

\section{Reusability of extractant 3}

The possibility to reuse extractant $\mathbf{3}$ for several extraction cycles was examined concerning the example of $\mathrm{Lu}^{3+}$ extraction (Fig. 7). No significant alterations in the extraction efficiency 


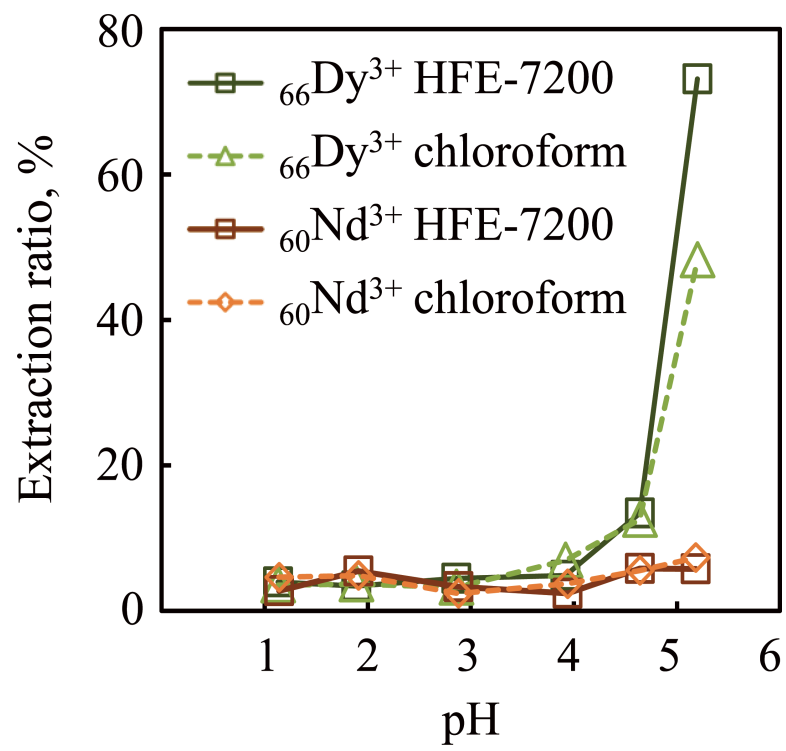

Fig. 5 Extraction ratio of Dy and Nd from water into HFE-7200 (solid line) or chloroform (dotted line) with $\mathbf{3}(6 \mathrm{mM})$ as a function of the aqueous $\mathrm{pH}$. The following buffer solutions were used: $\mathrm{pH} 1.1-$ 1.9, $\mathrm{HCl}-\mathrm{KCl}$ buffer; $\mathrm{pH} 2.9$, glycine-HCl buffer; $\mathrm{pH} 3.9$ - 5.2, acetate buffer.

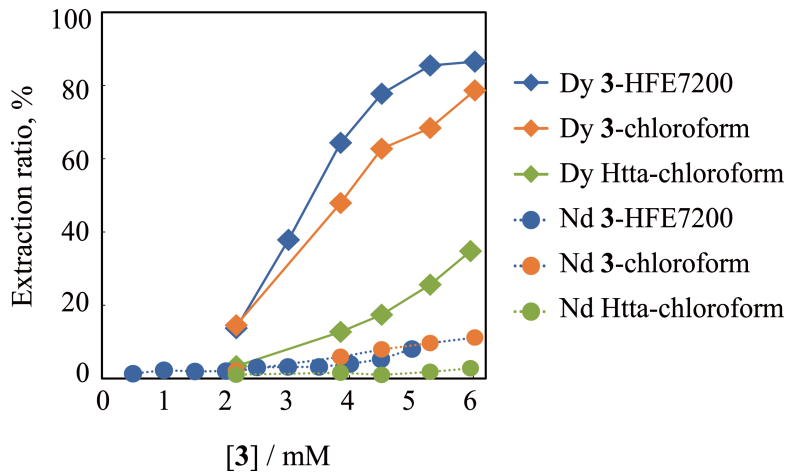

Fig. 6 Comparison of the extraction behavior for Dy and $\mathrm{Nd}$ using 3 or Htta in HFE-7200 or chloroform as a function of the extractant concentration ( $\mathrm{pH}$ of aqueous phase is 5.3).

were observed after three repeated cycles. This result indicates that $\mathbf{3}$ is applicable to the repeated extraction of lanthanide ions.

\section{Conclusions}

In order to evaluate the fundamental characteristics of a fluorous extraction system for lanthanide ions, the known $\beta$-diketone type compound $\mathbf{3}$ was used as a fluorophilic extractant. Lanthanide extraction experiments with the fluorous solvent HFE-7200 as an extraction media were conducted and the concentration-dependent extraction ratios for various lanthanide ions were confirmed. In the extraction of 5 heavy lanthanide ions ( $\mathrm{Lu}, \mathrm{Yb}, \mathrm{Tm}, \mathrm{Er}$ and $\mathrm{Ho}$ ), a 3:1 complex stoichiometry and the extraction constants were determined. Compared to a conventional organic solvent-based extraction system, significantly improved separation factors for Ho-lanthanide pairs were obtained. To the best of our knowledge, this is the

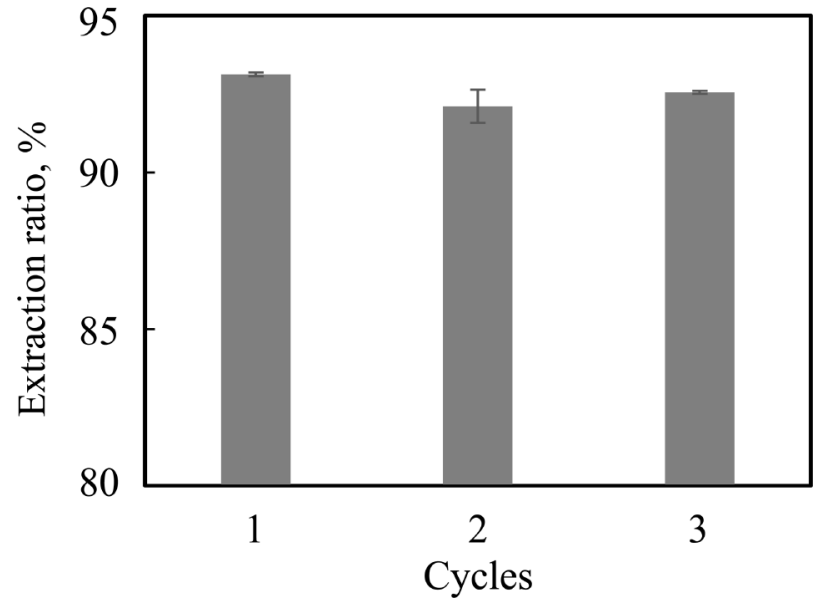

Fig. 7 Efficiencies for the repeated extraction of $3.6 \times 10^{-5} \mathrm{M} \mathrm{Lu}^{3+}$ in the fluorous solvent system: aqueous phase, $\mathrm{pH} 5.3$; fluorous phase, $5 \mathrm{mM}$ of 3; back extraction with $0.3 \mathrm{M} \mathrm{HNO}_{3}$.

first report on extraction constants of lanthanides using a fluorous solvent. Practically relevant separation of Dy and $\mathrm{Nd}$ was effective in the case of compound $\mathbf{3}$ combined with the fluorous solvent (HFE-7200) at a $\mathrm{pH}$ value of the aqueous phase around 5. It can be concluded that the 3/HFE-7200 system is a promising approach for the mutual separation of light lanthanides from middle or heavy lanthanide ions.

\section{Acknowledgements}

We gratefully acknowledge Dr. Hisashi Nemoto from the Chiba Prefectural Environmental Research Center for instrumental and experimental support with ICP-AES. We thank Dr. Mikiya Tanaka and Dr. Hirokazu Narita of AIST for helpful discussions.

\section{Supporting Information}

Electronic Supplementary Information (ESI) available: ${ }^{1} \mathrm{H}-\mathrm{NMR}$ spectra, ${ }^{13} \mathrm{C}$-NMR spectra, ${ }^{19} \mathrm{~F}-\mathrm{NMR}$ spectra. This material is available free of charge on the Web at http://www.jsac.or.jp/ analsci/.

\section{References}

1. V. R. Sastri, J. R. Perumareddi, V. R. Rao, G. V. S. Rayudu, and J.-C. G. Bünzli, "Modern aspects of rare earths and their complexes", 2003, Elsevier.

2. J.-C. G. Bünzli, Acc. Chem. Res., 2006, 39, 53.

3. K. Binnemans, Chem. Rev., 2009, 109, 4283.

4. G. S. Lee, M. Uchikoshi, K. Mimura, and M. Isshiki, Sep. Purif. Technol., 2009, 67, 79.

5. F. E. Kosinski and H. Bostian, J. Inorg. Nucl. Chem., 1969, 31, 3623.

6. K. Yoshizuka, Y. Sakamoto, Y. Baba, K. Inoue, and F. Nakashio, Ind. Eng. Chem. Res., 1992, 31, 1372

7. Y. Hasegawa, S. Tamaki, H. Yajima, B. Hashimoto, and T. Yaita, Talanta, 2011, 85, 1543.

8. G. F. Gagabe, K. Satoh, and K. Sawada, Talanta, 2011, 84, 1047.

9. H. Naganawa, K. Shimojo, and H. Mitamura, Solvent Extr. 
Res. Dev. Jpn., 2007, 14, 151.

10. K. Shimojo, H. Naganawa, J. Noro, F. Kubota, and M. Goto, Anal. Sci., 2007, 23, 1427.

11. K. Shimojo, N. Aoyagi, T. Saito, H. Okamura, F. Kubota, M. Goto, and H. Naganawa, Anal. Sci., 2014, 30, 263.

12. S. Nakamura and N. Suzuki, Polyhedron, 1988, 7, 155.

13. T. M. Samy, H. Imura, and N. Suzuki, J. Radioanal. Nucl. Chem., 1988, 126, 153.

14. G. F. Gagabe, Y. Satoh, K. Satoh, and K. Sawada, Monatsh. Chem., 2006, 137, 1015.

15. A. M. Poskanzer and B. M. Foreman Jr, J. Inorg. Nucl. Chem., 1961, 16, 323.

16. M. Atanassova and I. L. Dukov, Sep. Sci. Technol., 2005, 40, 1103.

17. M. Atanassova and I. Dukov, J. Solution Chem., 2009, 38, 289

18. M. Atanassova, N. Vassilev, and I. Dukov, Sep. Purif. Technol., 2011, 78, 214.

19. H. Okamura, N. Hirayama, K. Morita, K. Shimojo, H. Naganawa, and H. Imura, Anal. Sci., 2010, 26, 607.

20. K. Nakashima, F. Kubota, T. Maruyama, and M. Goto, Anal. Sci., 2003, 19, 1097.

21. X. Sun, H. Luo, and S. Dai, Talanta, 2012, 90, 132.

22. Y. Baba, F. Kubota, N. Kamiya, and M. Goto, J. Chem. Eng. Jpn., 2011, 44, 679 .

23. J. A. Gladysz, D. P. Curran, and I. T. Horváth, Chapter,
2011, 4, 56.

24. W. Zhang, Chem. Rev., 2009, 109, 749.

25. D. P. Curran, J. Fluorine Chem., 2008, 129, 898.

26. K. L. O'Neal, H. Zhang, Y. Yang, L. Hong, D. Lu, and S. G. Weber, J. Chromatogr., 2010, 1217, 2287.

27. I. T. Horváth, Acc. Chem. Res., 1998, 31, 641.

28. I. T. Horváth and J. Rábai, Science, 1994, 266, 72.

29. K. L. O’Neal, S. Geib, and S. G. Weber, Anal. Chem., 2007, 79, 3117

30. M. Matsumoto, Y. Tsujii, and K. Kondo, Solvent Extr. Res. Dev. Jpn., 2007, 14, 57.

31. P. G. Boswell and P. Bühlmann, J. Am. Chem. Soc., 2005, 127,8958

32. T. Kinoshita, S. Akita, S. Nii, F. Kawaizumi, and K. Takahashi, J. Chem. Eng. Jpn., 2005, 38, 94.

33. T. Kida, Y. Inaba, W. Watanabe, Y. Nakajima, S. Fukuoka, K. Takeshita, and A. Mori, Chem. Lett., 2010, 39, 774.

34. T. Maruyama, K. Nakashima, F. Kubota, and M. Goto, Anal. Sci., 2007, 23, 763.

35. S. B. Meshkova, V. E. Kuz'min, Y. E. Shapiro, Z. M. Topilova, I. V. Yudanova, D. V. Bol'shoi, and V. P. Antonovich, J. Anal. Chem., 2000, 55, 102.

36. S. B. Meshkova, Z. M. Topilova, M. O. Lozinskii, and D. V. Bol'shoi, J. Appl. Spectrosc., 1997, 64, 229.

37. S. Nakamura and N. Suzuki, Inorg. Chim. Acta, 1986, 114, 101 . 